\title{
Impact of Oncoplastic Breast Surgery on Rate of Complications, Time to Adjuvant Treatment, and Risk of Recurrence
}

\author{
Ida Oberhauser ${ }^{\mathrm{a}-\mathrm{c}}$ Jasmin Zeindler ${ }^{\mathrm{a}-\mathrm{c}}$ Mathilde Ritter ${ }^{\mathrm{a}-\mathrm{c}}$ Jeremy Levy ${ }^{\mathrm{d}}$ \\ Giacomo Montagna $^{a}$ b, e Robert Mechera ${ }^{a-c}$ Savas Deniz Soysal ${ }^{a-c}$ \\ Liliana Castrezana López ${ }^{a-c}$ Veronica D'Amico ${ }^{a-c}$ Elisabeth Artemis Kappos ${ }^{a, b}, f$ \\ Fabienne Dominique Schwab a, b, e Madleina Müller ${ }^{a, b, e} \quad$ Christian Kurzeder $^{\text {a, b, e }}$ \\ Martin Hauga, b, f Walter Paul Weber ${ }^{a-c}$ \\ ${ }^{a}$ Breast Center, University Hospital of Basel, Basel, Switzerland; ${ }^{b}$ University of Basel, Basel, Switzerland; ${ }^{c}$ Department \\ of Breast Surgery, University Hospital of Basel, Basel, Switzerland; ${ }^{d}$ Biometrical Practice BIOP, Basel, Switzerland; \\ e Department of Obstetrics and Gynecology, University Hospital of Basel, Basel, Switzerland; ${ }^{f}$ Department of Plastic, \\ Reconstructive, Aesthetic and Hand Surgery, University Hospital of Basel, Basel, Switzerland
}

\section{Keywords \\ Breast cancer · Oncoplastic breast surgery · Delay of treatment · Complications of breast cancer surgery · Recurrence of breast cancer}

\begin{abstract}
Background: The aim of this study was to compare the risk of complications and recurrence between oncoplastic and conventional breast surgery. Methods: This is a retrospective analysis of a consecutive series of 436 patients with stage I-III breast cancer who underwent surgery at the University Hospital of Basel between 2011 and 2018. Results: The nipple/ skin-sparing mastectomy (NSM/SSM) group showed significantly more delayed wound healing ( 32.7 vs. $5.8 \%, p<0.001$ ) and skin necrosis ( 13.9 vs. $1.9 \%, p=0.020$ ) compared to conventional mastectomy $(\mathrm{CM})$, which corresponded to significantly higher odds of short-term complications (OR 2.34, 95\% $\mathrm{Cl} 1.02-5.35, p=0.044)$. The incidence rate of long-term morbidity in oncoplastic breast-conserving surgery (OBCS) was significantly higher compared to conventional breast-conserving surgery (CBCS; 25.5 vs. 11.3 per 100 patient years [PY], $p<0.001$ ), in particular concerning chronic pain (13.3 vs. 6.6, $p=0.011$ ) and lymphedema ( 4.1 vs. $0.4, p=0.003$ ). Seroma as
\end{abstract}

karger@karger.com www.karger.com/brc

Karger $\%$

BOPEN ACCESS
(C) 2020 S. Karger AG, Basel

This is an Open Access article licensed under the Creative Common Attribution-NonCommercial-4.0 International License (CC BY-NC) (http://www.karger.com/Services/OpenAccessLicense), applicable to the online version of the article only. Usage and distribution for commercial purposes requires written permission. a long-term morbidity occurred more often in the CM group compared to the NSM/SSM group (5.8 vs. 0.5 per 100 PY, $p=$ 0.004). Patients received adjuvant treatment earlier after $C M$ compared to NSM/SSM (HR 1.83, 95\% Cl 1.05-3.19, $p=0.034$ ). There were no significant differences in the incidence of positive margins nor in the odds of recurrence after OBCS versus CBCS and after NSM/SSM versus CM. Conclusions: Even though the present study confirmed expected differences in complications and morbidity, it suggested that oncoplastic surgery is oncologically safe. Patients undergoing NSM/SSM should be followed closely to allow early detection and treatment of frequently associated complications and ensure timely start of adjuvant therapy.

(c) 2020 The Author(s)

Published by S. Karger AG, Basel

\section{Introduction}

The most common cancer among women worldwide is breast cancer, which causes $14 \%$ of all cancer-related deaths $[1,2]$. Major treatment progress has been achieved

I.O., J.Z., and M.R. contributed equally to this study. 
Table 1. Patient, tumor, and treatment characteristics by group of surgery

\begin{tabular}{|c|c|c|c|c|c|c|}
\hline & \multicolumn{3}{|c|}{ Breast conserving surgery $(n=283)$} & \multicolumn{3}{|l|}{ Mastectomy $(n=153)$} \\
\hline & $\begin{array}{l}\text { CBCS } \\
(n=95)\end{array}$ & $\begin{array}{l}\text { OBCS } \\
(n=188)\end{array}$ & $\begin{array}{l}p \\
\text { value }\end{array}$ & $\begin{array}{l}\mathrm{CM} \\
(n=52)\end{array}$ & $\begin{array}{l}\text { NSM/SSM } \\
(n=101)\end{array}$ & $\begin{array}{l}p \\
\text { value }\end{array}$ \\
\hline Median patient age (Q1-Q3), years & $62.0(51.0-72.0)$ & $61.0(50.0-70.0)$ & 0.633 & $69.0(59.5-80)$ & $51.0(44.0-61.0)$ & $<0.001$ \\
\hline \multicolumn{7}{|l|}{ T stage, $n(\%)^{\mathrm{a}}$} \\
\hline pTis & $11(11.6)$ & $24(12.8)$ & 0.419 & $6(11.5)$ & $20(19.8)$ & 0.003 \\
\hline pT0 & $6(6.3)$ & $8(4.3)$ & & $1(1.9)$ & $6(5.9)$ & \\
\hline pT1 & $60(63.2)$ & $109(58.0)$ & & $11(21.2)$ & $41(40.6)$ & \\
\hline pT2 & $18(18.9)$ & $40(21.3)$ & & $24(46.2)$ & $26(25.7)$ & \\
\hline pT3 & $0(0.0)$ & $6(3.2)$ & & $7(13.5)$ & $8(7.9)$ & \\
\hline pT4 & $0(0.0)$ & $0(0.0)$ & & $3(5.8)$ & $0(0.0)$ & \\
\hline \multicolumn{7}{|l|}{$\mathrm{N}$ stage, $n(\%)^{\mathrm{a}}$} \\
\hline $\mathrm{pNX}$ & $11(11.6)$ & $12(6.4)$ & 0.056 & $8(15.4)$ & $4(4.0)$ & 0.008 \\
\hline pNo & $64(67.4)$ & $138(73.4)$ & & $19(36.5)$ & $64(63.4)$ & \\
\hline $\mathrm{pN} 1$ & $17(17.9)$ & $27(14.4)$ & & $15(28.8)$ & $22(21.8)$ & \\
\hline $\mathrm{pN} 2$ & $3(3.2)$ & $2(1.1)$ & & $5(9.6)$ & $7(6.9)$ & \\
\hline $\mathrm{pN} 3$ & $0(0.0)$ & $8(4.3)$ & & $5(9.6)$ & $4(4.0)$ & \\
\hline \multicolumn{7}{|l|}{ Tumor grade, $n(\%)^{\mathrm{b}}$} \\
\hline I & $24(25.3)$ & $46(24.5)$ & 0.460 & $5(9.6)$ & $20(19.8)$ & 0.184 \\
\hline II & $44(46.3)$ & $81(43.1)$ & & $26(50.0)$ & $38(37.6)$ & \\
\hline III & $21(22.1)$ & $57(30.3)$ & & $20(38.5)$ & $39(38.6)$ & \\
\hline \multicolumn{7}{|l|}{ Cancer biology, $n(\%)^{\mathrm{c}}$} \\
\hline Pure DCIS & $11(11.6)$ & $23(12.2)$ & 0.920 & $5(9.6)$ & $19(18.8)$ & 0.180 \\
\hline Luminal A-like & $50(52.6)$ & $91(48.4)$ & & $19(36.5)$ & $37(36.6)$ & \\
\hline Luminal B-like (Her2-negative) & $21(22.1)$ & $40(21.3)$ & & $17(32.7)$ & $23(22.8)$ & \\
\hline Luminal B-like (Her2-positive) & $6(6.3)$ & $15(8.0)$ & & $5(9.6)$ & $7(6.9)$ & \\
\hline Her2-positive (nonluminal) & $2(2.1)$ & $9(4.8)$ & & $3(5.8)$ & $2(2.0)$ & \\
\hline Basal like & $4(4.2)$ & $9(4.8)$ & & $2(3.8)$ & $12(11.9)$ & \\
\hline \multicolumn{7}{|l|}{ Margin after initial surgery, $n(\%)$} \\
\hline Negative & $85(89.5)$ & $162(86.2)$ & 0.571 & $50(96.2)$ & $94(93.1)$ & 0.719 \\
\hline Positive & $10(10.5)$ & $26(13.8)$ & & $2(3.8)$ & $7(6.9)$ & \\
\hline \multicolumn{7}{|l|}{ Lymph node surgery, $n(\%)^{\mathrm{a}}$} \\
\hline None & $14(14.7)$ & $17(9.0)$ & 0.521 & $9(17.3)$ & $5(5.0)$ & 0.001 \\
\hline Sentinel lymph node biopsy & $68(71.6)$ & $142(75.5)$ & & $19(36.5)$ & $68(67.3)$ & \\
\hline Tailored axillary surgery ${ }^{\mathrm{d}}$ & $6(6.3)$ & $11(5.9)$ & & $3(5.8)$ & $6(5.9)$ & \\
\hline Axillary lymph node dissection & $7(7.4)$ & $17(9.0)$ & & $21(40.4)$ & $22(21.8)$ & \\
\hline \multicolumn{7}{|l|}{ Chemotherapy, $n$ (\%) } \\
\hline No chemotherapy & $76(80.0)$ & $140(74.5)$ & 0.590 & $35(67.3)$ & $64(63.4)$ & 0.388 \\
\hline Adjuvant chemotherapy & $10(10.5)$ & $31(16.5)$ & & $14(26.9)$ & $22(21.8)$ & \\
\hline Neoadjuvant chemotherapy & $8(8.4)$ & $15(8.0)$ & & $3(5.8)$ & $14(13.9)$ & \\
\hline Both & $1(1.1)$ & $2(1.1)$ & & $0(0.0)$ & $1(1.0)$ & \\
\hline Adjuvant radiotherapy, $n(\%)$ & $74(77.9)$ & $161(85.6)$ & 0.130 & $19(36.5)$ & $34(33.7)$ & 0.724 \\
\hline Median time of follow-up (Q1-Q3), months & $34.46(9.10-55.69)$ & $21.13(6.37-35.42)$ & 0.004 & $18.15(11.22-47.08)$ & $22.93(8.71-40.48)$ & 0.731 \\
\hline
\end{tabular}

DCIS, ductal carcinoma in situ. Missing: ${ }^{\mathrm{a}} 1,{ }^{\mathrm{b}} 15,{ }^{\mathrm{c}} 4 .{ }^{\mathrm{d}}$ Tailored axillary surgery as surgical intervention in the TAXIS trial [30].

over the past 30 years, leading to improved survival [3,4]. Systemic and radiation therapies have experienced dramatic paradigm changes in the past 2 decades, and surgical techniques have been refined as well $[3,5,6]$.

Oncoplastic breast surgery (OPS) has been developed to improve cosmetic outcomes after breast cancer surgery [7-9]. The term is often used to describe all types of breast surgery that involve immediate reconstruction by displacing or replacing volume of the ipsilateral breast, either with or without surgery of the contralateral breast $[6$,
$10,11]$. As such, nipple- as well as skin-sparing mastectomy (NSM/SSM) with immediate reconstruction are often included in the OPS category [12]. A more restricted definition of OPS refers to oncoplastic breast-conserving surgery (OBCS), which differs from conventional breastconserving surgery (CBCS) by the use of more extensive partial breast reconstruction techniques $[7,13,14]$. OBCS often involves nononcological skin resection and highvolume tumorectomy [13]. Therefore, OPS is an escalation of surgery compared to conventional breast surgery. 
Table 2. Short-term complications by group of surgery

\begin{tabular}{|c|c|c|c|c|c|c|}
\hline & \multicolumn{3}{|c|}{ Breast conserving surgery $(n=283)$} & \multicolumn{3}{|c|}{ Mastectomy $(n=153)$} \\
\hline & $\begin{array}{l}\text { CBCS } \\
(n=95)\end{array}$ & $\begin{array}{l}\text { OBCS } \\
(n=188)\end{array}$ & $p$ value & $\begin{array}{l}\mathrm{CM} \\
(n=52)\end{array}$ & $\begin{array}{l}\text { NSM/SSM } \\
(n=101)\end{array}$ & $p$ value \\
\hline Short-term complications, $n(\%)$ & $14(14.7)$ & $30(16.0)$ & 0.863 & $16(30.8)$ & $43(42.6)$ & 0.166 \\
\hline Relevant seroma $a^{\text {a, b }}$ & $3(3.2)$ & $14(7.4)$ & 0191 & $11(21.2)$ & $12(11.9)$ & 0.154 \\
\hline Delayed wound healing & $2(2.1)$ & $14(7.4)$ & 0.099 & $3(5.8)$ & $33(32.7)$ & $<0.001$ \\
\hline Infection & $4(4.2)$ & $8(4.3)$ & 1.000 & $5(9.6)$ & $12(11.9)$ & 0.790 \\
\hline Relevant hematoma $^{\mathrm{a}}$ & $6(6.3)$ & $6(3.2)$ & 0.226 & $1(1.9)$ & $12(11.9)$ & 0.062 \\
\hline Skin necrosis & $1(1.1)$ & $2(1.1)$ & 1.000 & $1(1.9)$ & $14(13.9)$ & 0.020 \\
\hline Flap loss & $0(0.0)$ & $0(0.0)$ & 1.000 & $0(0.0)$ & $5(5.0)$ & 0.167 \\
\hline Nipple necrosis & $0(0.0)$ & $1(0.5)$ & 1.000 & $0(0.0)$ & $2(2.0)$ & 0.548 \\
\hline
\end{tabular}

a Seroma or hematoma requiring intervention and/or causing discomfort. ${ }^{b}$ Drainages were removed as soon as a flow rate of $<20 \mathrm{~mL}$ over $24 \mathrm{~h}$ was reached.

It is unclear if this affects safety in terms of short- and long-term morbidity and oncologic outcomes $[10,15]$.

The aim of this study was to compare the rate of complications, time to adjuvant treatment, and risk of recurrence between OPS and conventional breast surgery.

\section{Materials and Methods}

\section{Study Design and Patients}

We performed a retrospective analysis of a consecutive cohort of patients with breast cancer, who were operated by 3 breast surgeons (W.P.W., S.D.S., and R.M.) at the University Hospital of Basel, a tertiary referral center in Switzerland, between 2011 and 2018. Women with American Joint Committee on Cancer (AJCC) stage I-III breast cancer were included. Patient, tumor, treatment, and outcome variables were recorded via the online good clinical practice conform clinical data management system secuTrial ${ }^{\circledR}$, which is maintained by the Clinical Trial Unit Basel. The classification of the 2013 St. Gallen Consensus Conference was used to define luminal $\mathrm{A}$, luminal B/HER2 negative, luminal B/HER2 positive, HER2 positive, and triple negative subtypes [16]. Adverse events were divided into short-term complications (within 30 days after surgery) and long-term morbidity ( $>30$ days after surgery). Time to adjuvant treatment was defined as the time period between first surgery and start of first adjuvant therapy, either radioor chemotherapy. Tumor-free margins were defined as $\geq 2 \mathrm{~mm}$ for ductal carcinoma in situ and no ink on tumor for invasive cancer. Surgical categories followed the previously described standardized nomenclature of OPS [17]. In short, oncoplastic tumorectomy differed from conventional tumorectomy by use of glandular flaps or volume replacement techniques, while oncoplastic mastopexy was defined by use of nononcologic skin excision. Reduction mammoplasty was defined by use of glandular flaps as well as nononcologic skin and tissue resection. SSM referred to the conservation of the skin envelope without nipple, while NSM consisted of both skin and nipple preservation.

\section{Statistical Analysis}

All analyses were performed on the 436 first consecutive patients recorded in the secuTrial ${ }^{\circledR}$ database. Demographics, baseline characteristics, disease characteristics, and response to thera- py were summarized descriptively by the occurrence of surgeryrelated adverse events (short-term complications and long-term morbidity), of recurrences, of adjuvant therapies, and by type of surgical procedure. Categorical variables were summarized by absolute frequencies and percentages. Continuous variables were summarized by median values and interquartile ranges (IQR). Occurrences were compared using Fisher's exact tests. Median values were compared using Wilcoxon test. Generated $p$ values were not corrected for multiple testing. Exposure-adjusted incidence rates were calculated per 100 patient years (PY) regarding long-term morbidity and recurrence. Incidence rates were compared using Fisher's exact test.

Logistic regression models were generated in order to identify potential predictors for the occurrence of surgery-related adverse events or recurrence. Type of surgery was included into each model as covariate. Additional covariates (age at baseline, diabetes status, smoking status, nodal stage, T stage, and margin, partly duration of follow-up) were entered based on stepwise selection. Odds ratios (OR) and corresponding 95\% confidence intervals (CI) for significant parameters were entered into a forest plot. A Cox model regression was generated in order to identify potential predictors for time to adjuvant therapy. Type of surgery was included into the model as covariate. Additional covariates (age at baseline, diabetes status, smoking status, nodal stage, T stage, and margin) were entered based on stepwise selection. Hazard ratios (HR) and corresponding 95\% CIs for significant parameters were entered into a forest plot.

\section{Results}

\section{Patient, Tumor, and Treatment Characteristics by Type of Surgery}

In total, 436 patients were included in this study. Median follow-up was 22.8 months (IQR 8.0-40.9). Patient, tumor, and treatment characteristics by group of surgery are demonstrated in Table 1. Detailed surgical procedures are listed in online supplementary Table 1 (see www.karger.com/doi/10.1159/000511728 for all online suppl. material). 


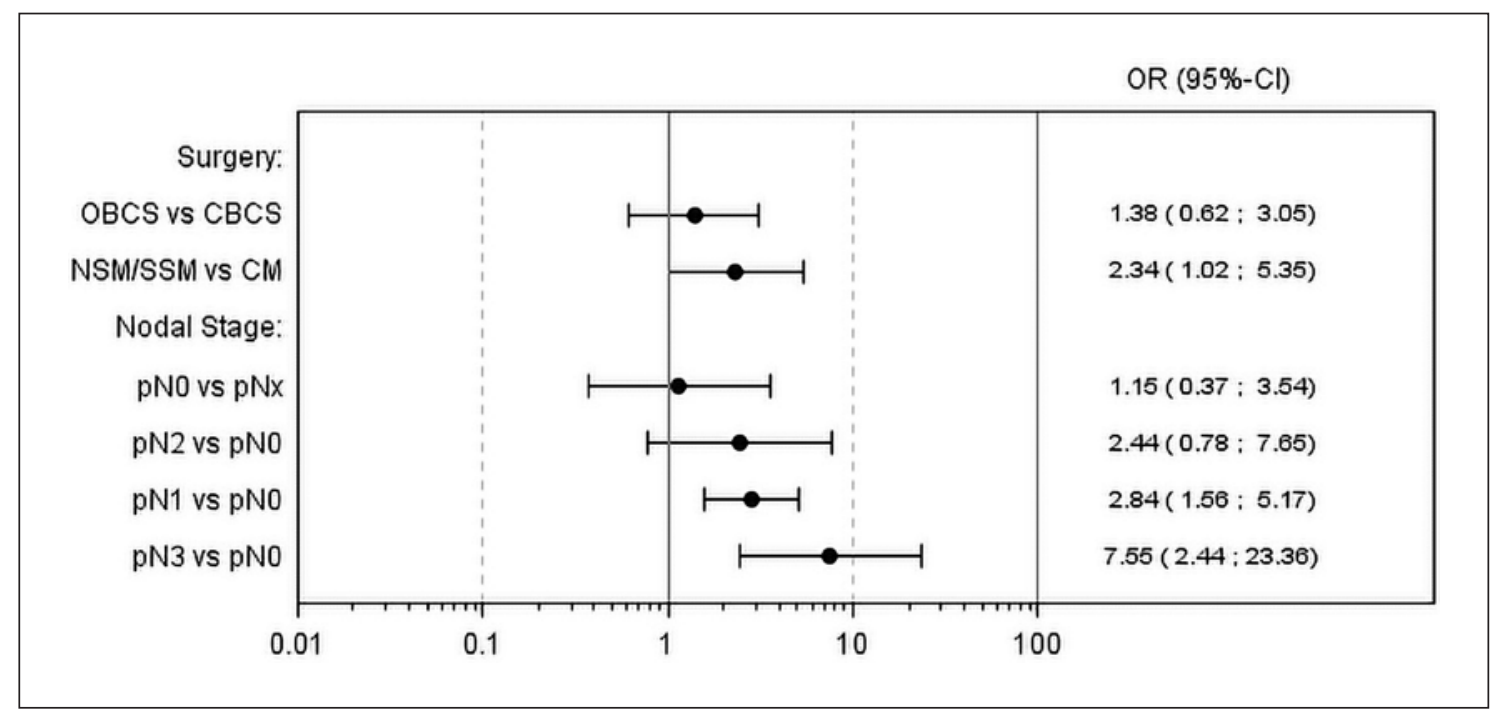

Fig. 1. Multivariate analysis for short-term complications. Type of surgery was included in the model as covariate. Additional covariates, including age at baseline, diabetes (yes/no), smoking (yes/no/prior), nodal stage ( $\mathrm{pNx} /$ $\mathrm{pN} 0 / \mathrm{pN} 1 / \mathrm{pN} 2 / \mathrm{pN} 3)$, T stage (pTis/pT0/pT1/pT2/pT3/pT4), and margin (+/-), were entered into the model based on the stepwise selection. Twenty-nine observations were deleted due to missing values.

Patients undergoing NSM/SSM were significantly younger $(p<0.001)$ and had lower tumor stages $(p=0.003$ for $\mathrm{T}$ stage and $p=0.008$ for $\mathrm{N}$ stage) compared to patients in the conventional mastectomy (CM) group without immediate reconstruction. Accordingly, axillary dissection was more frequently performed in the CM group $(p=0.001)$. The groups of OBCS and CBCS were comparable at baseline and differed only in time of follow-up (median follow-up time 34.5 vs. 21.1 months, $p=0.004$ ).

\section{Short-Term Complications}

Table 2 shows the occurrence of surgical short-term complications by type of surgery. There was no significant difference between OBCS and CBCS in terms of overall short-term complications ( $p=0.863$ ) or within the individual types of complications. Even though the NSM/ SSM group did not show significantly more overall shortterm complications compared to CM $(p=0.166)$, delayed wound healing $(p<0.001)$ and skin necrosis $(p=0.002)$ occurred significantly more often after NSM/SSM.

Multivariate analysis (Fig. 1) did not show a significant difference in short-term complications between OBCS and CBCS (OR 1.38, 95\% CI 0.62-3.05, $p=0.431$ ). However, there was a significant difference between NSM/ SSM and CM (OR 2.34, 95\% CI 1.02-5.35, $p=0.044$ ). Furthermore, there were significant associations between increasing nodal stage and the occurrence of short-term complications (pN1 vs. pN0: OR 2.84, 95\% CI 1.56-5.17, $p=0.001 ; \mathrm{pN} 2$ vs. pN0: OR $2.44,95 \%$ CI $0.78-7.65, p=$ 0.127; pN3 vs. pN0: OR 7.55, 95\% CI 2.44-23.36, $p<$ $0.001)$.

\section{Long-Term Morbidity}

There was a significantly higher exposure-adjusted incidence rate per $100 \mathrm{PY}$ for long-term morbidity (Table 3 ) in the OBCS versus CBCS group (25.5 vs. 11.3 per 100 PY, $p<0.001)$, in particular concerning chronic pain (13.3 vs. 6.6 per $100 \mathrm{PY}, p=0.011$ ) and lymphedema (4.1 vs. 0.4 per $100 \mathrm{PY}, p=0.003$ ). When comparing $\mathrm{CM}$ and NSM/SSM, overall long-term morbidity did not differ (29.6 vs. 27.9 per $100 \mathrm{PY}, p=0.832$ ), but the CM group had a significantly higher incidence rate of relevant seroma (5.8 vs. 0.5 per $100 \mathrm{PY}, p=0.004$ ).

Multivariate analysis for long-term morbidity (online suppl. Fig. 1) showed no significant differences between the surgical groups. Significant associations were found concerning increasing nodal stage and younger age. There was no significant association found concerning duration of follow-up.

Online supplementary Table 2 shows patient, tumor, and treatment characteristics by adverse events related to surgery.

\section{Time to Adjuvant Treatment}

Time to adjuvant treatment overall and time to adjuvant radiotherapy in particular did not differ significantly in CBCS versus OBCS and in NSM/SSM versus CM (Table 4). However, time to adjuvant chemotherapy was significantly prolonged in the NSM/SSM group compared to the CM group (42.5 days, IQR 32.0-54.0 vs. 30.0 days, IQR 27.0-34.0, $p=0.023$ ).

Multivariate analysis (Fig. 2) showed that patients of the $\mathrm{CM}$ group received adjuvant treatment earlier than 
Table 3. Exposure-adjusted incidence rate per 100 patient years for long-term morbidity by group of surgery

\begin{tabular}{|c|c|c|c|c|c|c|c|}
\hline & \multicolumn{7}{|c|}{ Breast conserving surgery $(n=283)$} \\
\hline & \multicolumn{3}{|c|}{ CBCS $(n=95)$, exposure $(d)=94,048$} & \multicolumn{4}{|c|}{ OBCS $(n=188)$, exposure $(d)=126,068$} \\
\hline & $\begin{array}{l}\text { patients with } \\
\text { events, } n(\%)\end{array}$ & $\begin{array}{l}\text { number of } \\
\text { events }\end{array}$ & $\begin{array}{l}\text { rate per } \\
100 \text { PYs }\end{array}$ & $\begin{array}{l}\text { patients with } \\
\text { events, } n(\%)\end{array}$ & $\begin{array}{l}\text { number of } \\
\text { events }\end{array}$ & $\begin{array}{l}\text { rate per } \\
100 \text { PYs }\end{array}$ & $p$ value \\
\hline Long-term morbidity & $25(26.3)$ & 29 & 11.3 & $56(29.8)$ & 88 & 25.5 & $<0.001$ \\
\hline Atrophy & $0(0.0)$ & 0 & 0.0 & $1(0.5)$ & 1 & 0.3 & 1.000 \\
\hline Axillary web syndrome & $0(0.0)$ & 0 & 0.0 & $3(1.6)$ & 4 & 1.2 & 0.141 \\
\hline Chronic pain & $15(15.8)$ & 17 & 6.6 & $40(21.3)$ & 46 & 13.3 & 0.011 \\
\hline Fat necrosis & $1(1.1)$ & 1 & 0.4 & $2(1.1)$ & 4 & 1.2 & 0.401 \\
\hline Fibrosis & $0(0.0)$ & 0 & 0.0 & $4(2.1)$ & 4 & 1.2 & 0.141 \\
\hline Impairment of shoulder mobility & $9(9.5)$ & 9 & 3.5 & $10(5.3)$ & 11 & 3.2 & 0.826 \\
\hline Lymphedema & $1(1.1)$ & 1 & 0.4 & $11(5.9)$ & 14 & 4.1 & 0.003 \\
\hline \multirow[t]{4}{*}{ Relevant seroma ${ }^{a}$} & $1(1.1)$ & 1 & 0.4 & $4(2.1)$ & 4 & 1.2 & 0.401 \\
\hline & \multicolumn{7}{|c|}{ Mastectomy $(n=153)$} \\
\hline & \multicolumn{3}{|c|}{ CM $(n=52)$, exposure $(d)=44,421$} & \multicolumn{4}{|c|}{ NSM/SSM $(n=101)$, exposure $(d)=78,605$} \\
\hline & $\begin{array}{l}\text { patients with } \\
\text { events, } n(\%)\end{array}$ & $\begin{array}{l}\text { number of } \\
\text { events }\end{array}$ & $\begin{array}{l}\text { rate per } \\
100 \text { PYs }\end{array}$ & $\begin{array}{l}\text { patients with } \\
\text { events, } n(\%)\end{array}$ & $\begin{array}{l}\text { number of } \\
\text { events }\end{array}$ & $\begin{array}{l}\text { rate per } \\
100 \text { PYs }\end{array}$ & $p$ value \\
\hline Long-term morbidity & $18(34.6)$ & 36 & 29.6 & $37(36.6)$ & 60 & 27.9 & 0.832 \\
\hline Abdominal hernia & $0(0.0)$ & 0 & 0.0 & $1(1.0)$ & 1 & 0.5 & 1.000 \\
\hline Atrophy & $0(0.0)$ & 0 & 0.0 & $1(1.0)$ & 1 & 0.5 & 1.000 \\
\hline Axillary web syndrome & $1(1.9)$ & 2 & 1.6 & $6(5.9)$ & 6 & 2.8 & 0.719 \\
\hline Chronic pain & $7(13.5)$ & 10 & 8.2 & $23(22.8)$ & 25 & 11.6 & 0.385 \\
\hline Fat necrosis & $0(0.0)$ & 0 & 0.0 & $2(2.0)$ & 2 & 0.9 & 0.539 \\
\hline Fibrosis & $0(0.0)$ & 0 & 0.0 & $1(1.0)$ & 1 & 0.5 & 1.000 \\
\hline Impairment of shoulder mobility & $7(13.5)$ & 8 & 6.6 & $14(13.9)$ & 15 & 7.0 & 1.000 \\
\hline Lymphedema & $7(13.5)$ & 9 & 7.4 & $5(5.0)$ & 6 & 2.8 & 0.063 \\
\hline Relaxatio & $0(0.0)$ & 0 & 0.0 & $1(1.0)$ & 2 & 0.9 & 0.539 \\
\hline Relevant seroma ${ }^{a}$ & $6(11.5)$ & 7 & 5.8 & $1(1.0)$ & 1 & 0.5 & 0.004 \\
\hline
\end{tabular}

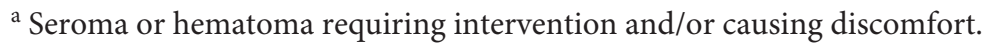

Table 4. Time to first adjuvant treatment by group of surgery

\begin{tabular}{|c|c|c|c|c|c|c|}
\hline & \multicolumn{3}{|c|}{ Breast conserving surgery $(n=283)$} & \multicolumn{3}{|c|}{ Mastectomy $(n=153)$} \\
\hline & $\begin{array}{l}\text { CBCS } \\
(n=95)\end{array}$ & $\begin{array}{l}\text { OBCS } \\
(n=188)\end{array}$ & $p$ value & $\mathrm{CM}(n=52)$ & $\begin{array}{l}\text { NSM/SSM } \\
(n=101)\end{array}$ & $p$ value \\
\hline \multicolumn{7}{|c|}{ Time to adjuvant chemotherapy } \\
\hline Number & 7 & 32 & & 13 & 22 & \\
\hline Median (Q1-Q3), days & $34.0(27.0-60.0)$ & $41.0(32.5-61.0)$ & 0.537 & $30.0(27.0-34.0)$ & $42.5(32.0-54.0)$ & 0.023 \\
\hline \multicolumn{7}{|c|}{ Time to adjuvant radiotherapy } \\
\hline Number & 54 & 114 & & 10 & 14 & \\
\hline Median (Q1-Q3), days & $46.5(37.0-60.0)$ & $47.0(39.0-60.0)$ & 0.447 & $60.0(43.0-63.0)$ & $50.5(40.0-68.0)$ & 0.908 \\
\hline \multicolumn{7}{|l|}{ Time to adjuvant treatment $\mathrm{t}^{\mathrm{a}}$} \\
\hline Number & 61 & 146 & & 23 & 36 & \\
\hline Median (Q1-Q3), days & $46.0(34.0-60.0)$ & $47.0(39.0-61.0)$ & 0.501 & $39.0(30.0-60.0)$ & $45.5(37.0-60.0)$ & 0.172 \\
\hline
\end{tabular}




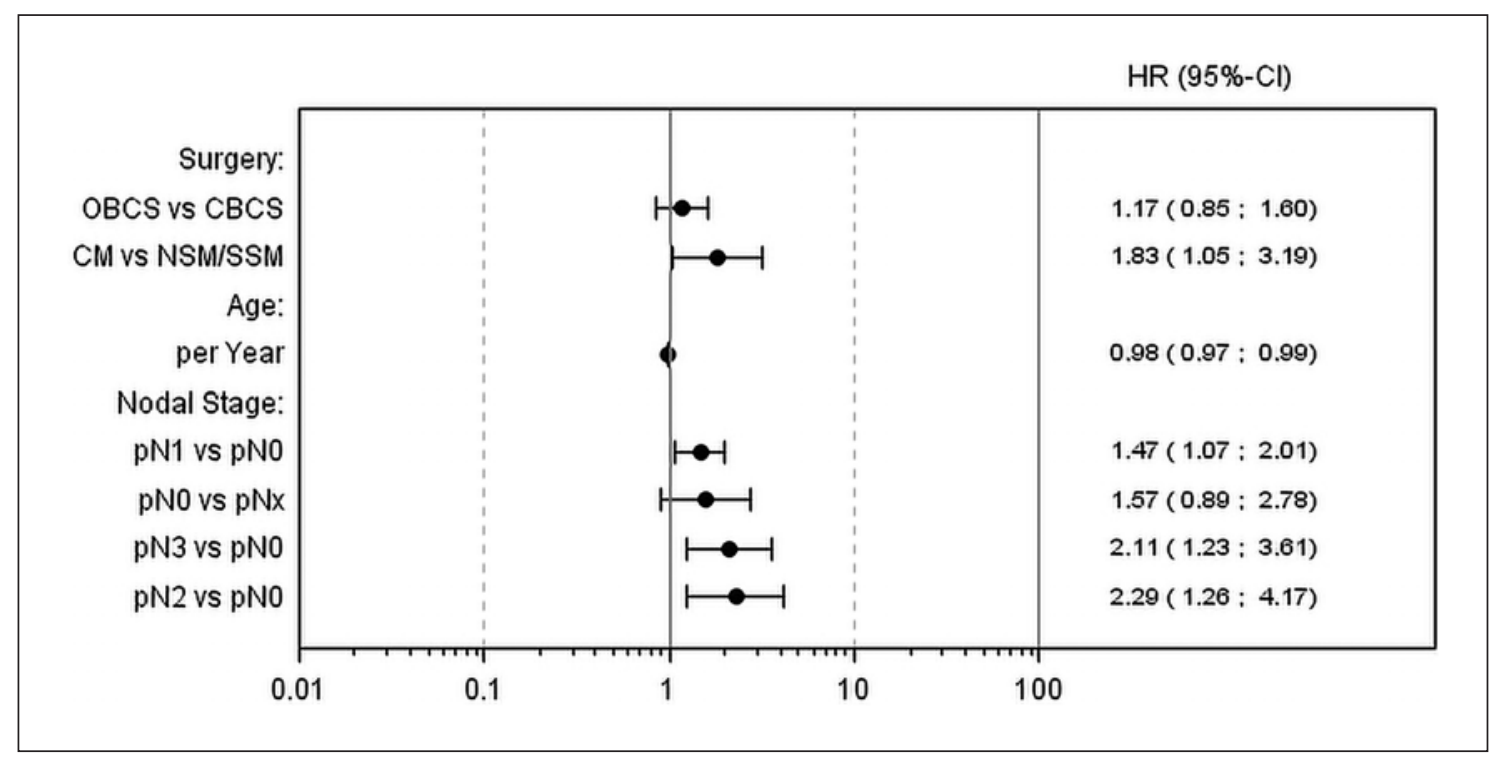

Fig. 2. Multivariate analysis for time to adjuvant therapy (radiation or chemotherapy). Type of surgery was included in the model as covariate. Additional covariates, including age at baseline, diabetes (yes/no), smoking (yes/no/prior), nodal stage ( $\mathrm{pNx} / \mathrm{pN} 0 / \mathrm{pN} 1 / \mathrm{pN} 2 / \mathrm{pN} 3$ ), T stage (pTis/pT0/pT1/pT2/pT3/pT4), and margin (+/), were entered into the model based on the stepwise selection. Sixty-three observations were deleted due to missing values.

patients of the NSM/SSM group (HR 1.83, 95\% CI 1.05$3.19, p=0.034)$. Significant associations were also found for nodal stage and age.

\section{Oncologic Outcomes}

There was no significant difference in the incidence of positive margins after OBCS versus CBCS $(p=0.571)$ or after NSM/SSM versus CM ( $p=0.719$; Table 1$)$. Overall, there were no significant differences in the exposure-adjusted incidence of recurrence between CBCS and OBCS and between CM and NSM/SSM (Table 5). Multivariate analysis confirmed the absence of significant differences between those groups (online suppl. Fig. 2). Longer follow-up, increasing nodal stage and age were associated with higher odds of recurrence.

\section{Discussion}

The present study compared OPS with conventional techniques in terms of short-term complications, longterm morbidity, time to adjuvant treatment, rate of positive margins, and risk of recurrence. Rate of positive margins and risk of recurrence did not differ significantly or relevantly between the groups.

However, patients undergoing NSM/SSM experienced a longer time to adjuvant chemotherapy than $\mathrm{CM}$ patients, presumably caused by increased risk of ischemic complications. In the individual patient, this delay may become relevant. Therefore, patients undergoing NSM/
SSM should be followed closely and complications treated promptly to ensure oncologic safety. Other studies did not show a delay of treatment in NSM/SSM in comparison with CM $[18,19]$. In 2018, the Oncoplastic Breast Consortium consensus expert panel was asked about risk factors for severe mastectomy skin flap necrosis. The panel considered the location of the incision, the amount and duration of pressure applied by retractors during surgery, the thickness of the skin flaps, and insufficient surgeon experience as relevant risk factors [12, 20,21], all of which are at least partially modifiable. In the present study, the main predictor of surgical complications besides NSM/ SSM was increasing axillary nodal stage. While the latter is explained by more radical surgery, the former is mainly driven by preservation of the skin envelope with associated necrosis. The rate of nipple or skin necrosis $(2.0$ or $13.9 \%$, respectively) in this study is well in line with findings from other studies [21].

OBCS showed a higher incidence rate of long-term morbidity than CBCS. This might be explained by the inclusion of complications attributed to axillary surgery, such as lymphedema and chronic pain in the arm or axilla. Previous studies mostly showed similar complication rates in OBCS versus CBCS, with the exception of delayed wound healing, which, however, did not differ in our study population $[22,23]$. Despite the higher complication rate, OBCS did not cause any delay of treatment when compared to CBCS, which is in accordance with prior studies [22]. All patients in this study were operated by the same team of breast surgeons who have specialized 
Table 5. Exposure-adjusted incidence rate per 100 patient years for recurrence by group of surgery

\begin{tabular}{|c|c|c|c|c|c|c|c|}
\hline & \multicolumn{7}{|c|}{ Breast conserving surgery $(n=283)$} \\
\hline & \multicolumn{3}{|c|}{ CBCS $(n=95)$, exposure $(d)=94,048$} & \multicolumn{4}{|c|}{ OBCS $(n=188)$, exposure $(d)=126,068$} \\
\hline & $\begin{array}{l}\text { patients with } \\
\text { events, } n(\%)\end{array}$ & $\begin{array}{l}\text { number } \\
\text { of events }\end{array}$ & $\begin{array}{l}\text { rate per } \\
100 \mathrm{PYs}\end{array}$ & $\begin{array}{l}\text { patients with } \\
\text { events, } n(\%)\end{array}$ & $\begin{array}{l}\text { number } \\
\text { of events }\end{array}$ & $\begin{array}{l}\text { rate per } \\
100 \text { PYs }\end{array}$ & $p$ value \\
\hline Recurrence & $6(6.3)$ & 6 & 2.3 & $9(4.8)$ & 9 & 2.6 & 1.000 \\
\hline Local & $4(4.2)$ & 4 & 1.6 & $4(2.1)$ & 4 & 1.2 & 0.731 \\
\hline Distant & $1(1.1)$ & 1 & 0.4 & $5(2.7)$ & 5 & 1.4 & 0.248 \\
\hline \multirow[t]{4}{*}{ Combined } & $1(1.1)$ & 1 & 0.4 & $0(0.0)$ & 0 & 0.0 & 0.427 \\
\hline & \multicolumn{7}{|c|}{ Mastectomy $(n=153)$} \\
\hline & \multicolumn{3}{|c|}{$\mathrm{CM}(n=52)$, exposure $(\mathrm{d})=44,421$} & \multicolumn{4}{|c|}{ NSM/SSM $(n=101)$, exposure $(d)=78,605$} \\
\hline & $\begin{array}{l}\text { patients with } \\
\text { events, } n(\%)\end{array}$ & $\begin{array}{l}\text { number } \\
\text { of events }\end{array}$ & $\begin{array}{l}\text { rate per } \\
100 \text { PYs }\end{array}$ & $\begin{array}{l}\text { patients with } \\
\text { events, } n(\%)\end{array}$ & $\begin{array}{l}\text { number } \\
\text { of events }\end{array}$ & $\begin{array}{l}\text { rate per } \\
100 \text { PYs }\end{array}$ & $p$ value \\
\hline Recurrence & $8(15.4)$ & 9 & 7.4 & $6(5.9)$ & 6 & 2.8 & 0.063 \\
\hline Local & $1(1.9)$ & 1 & 0.8 & $2(2.0)$ & 2 & 0.9 & 1.000 \\
\hline Loco-regional & $2(3.8)$ & 2 & 1.6 & $0(0.0)$ & 0 & 0.0 & 0.130 \\
\hline Regional & $0(0.0)$ & 0 & 0.0 & $2(2.0)$ & 2 & 0.9 & 0.539 \\
\hline Distant & $2(3.8)$ & 2 & 1.6 & $0(0.0)$ & 0 & 0.0 & 0.130 \\
\hline Combined & $4(7.7)$ & 4 & 3.3 & $2(2.0)$ & 2 & 0.9 & 0.198 \\
\hline
\end{tabular}

Local, reappearance of breast cancer in the ipsilateral breast (after breast-conserving surgery) or the ipsilateral chest wall (after mastectomy); regional, reappearance of breast cancer in the regional lymph nodes; loco-regional, reappearance of breast cancer in both ipsilateral chest wall and regional lymph nodes; distant, distant metastases; combined, combination of (loco-)regional and distant recurrence.

in oncoplastic surgery and the ratio of oncoplastic to conventional surgery seems to be high. Importantly, however, many procedures included nononcological skin resection or nipple recentralization in the absence of large-volume resections or reduction mammoplasty techniques. When comparing the different types of surgery, this study showed no differences in tumor recurrence, suggesting an overall similar safety profile throughout the different surgery groups. However, the median follow-up time of only 22.8 months must be considered. The comparable safety profile of the procedures is further reflected by the similar numbers of positive margins when comparing the different surgery groups, which is supported by some but not all previous studies [24-28].

The most important limitation of this study is the retrospective single-center observational study design. The selection bias inherent in this type of study is caused by both patients and surgeons. Younger patients tend to choose NSM/SSM to achieve better aesthetic results. Surgeons recommend CM without reconstruction in older patients with higher tumor stages to decrease the risk of adverse events related to more extensive surgery [27, 29]. Furthermore, the surgical groups showed varying followup times, which may have caused an attrition bias, especially concerning recurrence and long-term morbidity rates. We tried to adjust for differences between groups by performing multivariate analyses and exposure-adjusted incidence rates but realize that residual confounding is likely. Another limitation of this study is the inclusion of both ductal carcinoma in situ and invasive cancer, which could limit the informative value in terms of oncological safety due to the heterogeneity of the patient population.

\section{Conclusions}

While OBCS showed a higher incidence rate of longterm morbidity than CBCS, there were no significant or relevant differences in risk of complications, time to adjuvant treatment, and risk of recurrence. The increased risk of short-term complications after NSM/SSM, while being associated with time to adjuvant therapy, had no significant impact on risk of long-term morbidity or recurrence. We conclude that oncoplastic techniques are overall oncologically safe but recommend that patients undergoing NSM/SSM be followed closely to allow prompt diagnosis and treatment of complications in order to ensure timely adjuvant therapy. 


\section{Acknowledgement}

We thank Constantin Sluka and his team of the Clinical Trial Unit Basel for the management and maintenance of the online clinical data management system secuTrial ${ }^{\circledR}$.

\section{Statement of Ethics}

This research project complies with the guidelines for human studies according to the Declaration of Helsinki as revised in 2013. The study protocol was approved by the Ethics Committee of Northwest and Central Switzerland (Ethikkommission Nordwestund Zentralschweiz, EKNZ), and all subjects have given their written informed consent.

\section{Conflict of Interest Statement}

W.P.W. has received research support from Takeda Pharmaceuticals International via Swiss Group for Clinical Cancer Research (SAKK), honoraria/consultation from Genomic Health, Inc., USA, and support for conferences and meetings from Sandoz, Genomic Health, Medtronic, Novartis Oncology, and Pfizer. J.L. has received personal fees for his work by the Department of Breast Surgery, University Hospital of Basel. C.K. has received research support from Roche, Tessaro, Genomic Health, Pfizer, Astra Zeneca, GSK, and Lilly.

\section{Funding Sources}

This work was funded by the Department of Surgery, University Hospital of Basel. This funding source had no involvement in the study design; in the collection, analysis, and interpretation of data; in the writing of the report; and in the decision to submit the article for publication.

\section{Author Contributions}

Study concepts and design were contributed by Jasmin Zeindler, Savas Deniz Soysal, and Walter Paul Weber. Data was acquired by Ida Oberhauser, Mathilde Ritter, Madleina Maria Müller, Veronica D’Amico, and Giacomo Montagna. Quality control and analysis of data was conducted by Ida Oberhauser, Jasmin Zeindler, Mathilde Ritter, Jeremy Levy, and Walter Paul Weber. Statistical analysis was performed by Jeremy Levy. The manuscript was prepared by Ida Oberhauser, Jasmin Zeindler, Mathilde Ritter, Jeremy Levy, and Walter Paul Weber. All authors helped draft the work, revised it critically for important intellectual content, and read and approved the final version to be published. All authors agreed to be accountable for all aspects of the work in ensuring that questions related to the accuracy of any part of the work are appropriately investigated and resolved.

\section{References}

1 De La Cruz L, Blankenship SA, Chatterjee A, Geha R, Nocera N, Czerniecki BJ, et al. Outcomes After Oncoplastic Breast-Conserving Surgery in Breast Cancer Patients: A Systematic Literature Review. Ann Surg Oncol. 2016 Oct;23(10):3247-58.

2 Siegel RL, Miller KD, Jemal A. Cancer Statistics, 2017. CA Cancer J Clin. 2017 Jan;67(1): 7-30.

3 Tong CW, Wu M, Cho WC, To KK. Recent Advances in the Treatment of Breast Cancer. Front Oncol. 2018 Jun;8:227.

4 Bertuccio P, Alicandro G, Malvezzi M, Carioli G, Boffetta P, Levi F, et al. Cancer mortality in Europe in 2015 and an overview of trends since 1990. Ann Oncol. 2019 Aug;30(8): 1356-69.

5 Silverstein MJ. How I do it: oncoplastic breast-conservation surgery. Ann Surg Oncol. 2010 Oct;17(Suppl 3):242-4

6 Silverstein MJ. Oncoplastic Breast Surgery: From Oblivion to Mainstream. Ann Surg Oncol. 2019 Oct;26(11):3409-12.

7 Galimberti V, Zurrida S, Zanini V, Callegari M, Veronesi P, Catania S, et al. Central small size breast cancer: how to overcome the problem of nipple and areola involvement. Eur J Cancer. 1993;29A(8):1093-6.

8 Metcalfe KA, Cil TD, Semple JL, Li LD, Bagher S, Zhong T, et al. Long-Term Psychosocial Functioning in Women with Bilateral Prophylactic Mastectomy: Does Preservation of the Nipple-Areolar Complex Make a Difference? Ann Surg Oncol. 2015 Oct;22(10): 3324-30.
9 Bailey CR, Ogbuagu O, Baltodano PA, Simjee UF, Manahan MA, Cooney DS, et al. Qualityof-Life Outcomes Improve with Nipple-Sparing Mastectomy and Breast Reconstruction. Plast Reconstr Surg. 2017 Aug;140(2):219-26.

10 Haloua MH, Krekel NM, Winters HA, Rietveld DH, Meijer S, Bloemers FW, et al. A systematic review of oncoplastic breast-conserving surgery: current weaknesses and future prospects. Ann Surg. 2013 Apr;257(4):609-20.

11 Chatterjee A, Gass J, Patel K, Holmes D, Kopkash K, Peiris L, et al. A consensus definition and classification system of oncoplastic surgery developed by the American Society of Breast Surgeons. Ann Surg Oncol. 2019 Oct; 26(11):3436-44.

12 Weber WP, Haug M, Kurzeder C, BjelicRadisic V, Koller R, Reitsamer R, et al. Oncoplastic Breast Consortium consensus conference on nipple-sparing mastectomy. Breast Cancer Res Treat. 2018 Dec;172(3):523-37.

13 Anderson BO, Masetti R, Silverstein MJ. Oncoplastic approaches to partial mastectomy: an overview of volume-displacement techniques. Lancet Oncol. 2005 Mar;6(3):145-57.

14 Silverstein MJ, Mai T, Savalia N, Vaince F, Guerra L. Oncoplastic breast conservation surgery: the new paradigm. J Surg Oncol. 2014 Jul;110(1):82-9.

15 Khan J, Barrett S, Forte C, Stallard S, WeilerMithoff E, Doughty JC, et al. Oncoplastic breast conservation does not lead to a delay in the commencement of adjuvant chemotherapy in breast cancer patients. Eur J Surg Oncol. 2013 Aug;39(8):887-91.
16 Goldhirsch A, Winer EP, Coates AS, Gelber RD, Piccart-Gebhart M, Thürlimann B, et al.; Panel members. Personalizing the treatment of women with early breast cancer: highlights of the St Gallen International Expert Consensus on the Primary Therapy of Early Breast Cancer 2013. Ann Oncol. 2013 Sep;24(9): 2206-23.

17 Weber WP, Soysal SD, Fulco I, Barandun M, Babst D, Kalbermatten D, et al. Standardization of oncoplastic breast conserving surgery. Eur J Surg Oncol. 2017 Jul;43(7):1236-43.

18 Allweis TM, Boisvert ME, Otero SE, Perry DJ, Dubin NH, Priebat DA. Immediate reconstruction after mastectomy for breast cancer does not prolong the time to starting adjuvant chemotherapy. Am J Surg. 2002 Mar;183(3): 218-21.

19 Rey P, Martinelli G, Petit JY, Youssef O, De Lorenzi F, Rietjens M, et al. Immediate breast reconstruction and high-dose chemotherapy. Ann Plast Surg. 2005 Sep;55(3):250-4.

20 Colwell AS, Tessler O, Lin AM, Liao E, Winograd J, Cetrulo CL, et al. Breast reconstruction following nipple-sparing mastectomy: predictors of complications, reconstruction outcomes, and 5-year trends. Plast Reconstr Surg. 2014 Mar;133(3):496-506.

21 Matsen CB, Mehrara B, Eaton A, Capko D, Berg A, Stempel M, et al. Skin flap necrosis after mastectomy with reconstruction: a prospective study. Ann Surg Oncol. 2016 Jan; 23(1):257-64. 
22 Tenofsky PL, Dowell P, Topalovski T, Helmer SD. Surgical, oncologic, and cosmetic differences between oncoplastic and nononcoplastic breast conserving surgery in breast cancer patients. Am J Surg. 2014 Mar;207(3):398-402.

23 Piper M, Peled AW, Sbitany H. Oncoplastic breast surgery: current strategies. Gland Surg. 2015 Apr;4(2):154-63.

24 Clough KB, Lewis JS, Couturaud B, Fitoussi A, Nos C, Falcou MC. Oncoplastic techniques allow extensive resections for breast-conserving therapy of breast carcinomas. Ann Surg. 2003 Jan;237(1):26-34.

25 Yi M, Kronowitz SJ, Meric-Bernstam F, Feig BW, Symmans WF, Lucci A, et al. Local, regional, and systemic recurrence rates in patients undergoing skin-sparing mastectomy compared with conventional mastectomy. Cancer. 2011 Mar;117(5):916-24.

26 Chakravorty A, Shrestha AK, Sanmugalingam N, Rapisarda F, Roche N, Querci Della Rovere $\mathrm{G}$, et al. How safe is oncoplastic breast conservation? Comparative analysis with standard breast conserving surgery. Eur J Surg Oncol. 2012 May;38(5):395-8.

27 Carter SA, Lyons GR, Kuerer HM, Bassett RL Jr, Oates S, Thompson A, et al. Operative and oncologic outcomes in 9861 patients with operable breast cancer: single-institution analysis of breast conservation with oncoplastic reconstruction. Ann Surg Oncol. 2016 Oct; 23(10):3190-8.

28 Chen JY, Huang YJ, Zhang LL, Yang CQ, Wang K. Comparison of Oncoplastic Breast-
Conserving Surgery and Breast-Conserving Surgery Alone: A Meta-Analysis. J Breast Cancer. 2018 Sep;21(3):321-9.

29 McCarthy CM, Mehrara BJ, Riedel E, Davidge K, Hinson A, Disa JJ, et al. Predicting complications following expander/implant breast reconstruction: an outcomes analysis based on preoperative clinical risk. Plast Reconstr Surg. 2008 Jun;121(6):1886-92.

30 Henke G, Knauer M, Ribi K, Hayoz S, Gérard MA, Ruhstaller T, et al. Tailored axillary surgery with or without axillary lymph node dissection followed by radiotherapy in patients with clinically node-positive breast cancer (TAXIS): study protocol for a multicenter randomized phase-III trial. Trials. $2018 \mathrm{Dec}$; 19(1):667. 